\title{
Contrarreforma da Previdência Social sob o comando do capital financeiro
}

\section{Counter reformation of Social Security under financial capital command}

\author{
Maria Lucia Lopes da Silva \\ Assistente social, doutora em Política Social, professora da graduação em Serviço Social \\ e do mestrado e doutorado em Política Social do Programa de Pós-Graduação em Política \\ Social da Universidade de Brasília (UnB)/DF, Brasil. lucialopes198@gmail.com
}

\begin{abstract}
Resumo: Este texto trata do movimento de contrarreforma (restrições de direitos) referentes à Previdência Social iniciado na década de $1990 \mathrm{e}$ das propostas para o seu aprofundamento, com a $\mathrm{PEC} \mathrm{n}^{\circ}$ 287/2016, diante do agravamento da crise estrutural do capital, da crescente (e questionável) dívida pública e das pressões das instituições financeiras (bancos, fundos de pensão, entre outras), sobre o Estado, para reorientar o máximo possível o fundo público a seu favor e de outras frações do grande capital. Trata ainda de possíveis consequências sociais diante de uma eventual aprovação da $\mathrm{PEC} \mathrm{n}{ }^{\circ}$ 287/2016.
\end{abstract}

Palavras-chave: Crise. Direitos. Contrarreforma. Previdência Social. Capital.
Abstract: This text deals with the counter reformation movement (restrictions of rights) concerning social welfare started in the 1990s and the proposals for its deepening, with the Proposed Constitutional Amendment - PEC n ${ }^{\circ}$ 287/2016, in the face of the worsening structural crisis of capital, the growing (and questionable) public debt and the pressures of financial institutions (banks, pension funds, among others), on the State, in order to redirect as much as possible the public fund in its favor and other fractions of the big capital. It also discusses the possible social consequences of a probable approval of the referred $\mathrm{PEC} \mathrm{n^{ \circ }}$ 287/ 2016.

Keywords: Crisis. Rights. Counter Reformation. Social Security. Capital.

\section{Introdução}

restrição de direitos sociais tem sido recorrente nos países afeta-
dos pela crise estrutural do capital que se alastra desde o início
dos anos 1970 , com aprofundamento a partir de 2008. Em geral, acorrentados pelas expressivas dívidas públicas, os Estados-nação subordinam-se às pressões das finanças, que, associadas a grupos empresariais 
transnacionais comandam, no contexto da crise, a acumulação (Chesnais, 2001) e disputam ferozmente o fundo público. A Seguridade Social e, nesse particular, a Previdência Social tem sido uma das áreas mais afetadas. $\mathrm{O}$ Brasil não foge à regra.

Desde o final da década de 1990, sob pressões realizadas pelas instituições financeiras que atuam em esfera mundial, como o Fundo Monetário Internacional (FMI) e o Banco Mundial, além de outras instituições financeiras como bancos, seguradoras, fundos de pensão, sociedades hipotecárias, com atuação no país, o Estado brasileiro, possuidor de uma crescente (e questionável) dívida pública, ${ }^{1}$ vem promovendo uma incessante contrarreforma (redução de direitos) da Seguridade Social, com ênfase na Previdência Social, que tem provocado a redução do espaço da previdência pública e a ampliação do espaço da previdência privada (Silva, 2012 e 2015). Esse movimento de contrarreforma é oscilante, ora mais intenso e agressivo, ora mais sutil, dependendo da conjunção de fatores e do grau de comprometimento e capacidade de reação dos governos às pressões do capital financeiro, que se alimenta da dívida pública. A Proposta de Emenda Constitucional (PEC) $\mathrm{n}^{\mathrm{o}} 287$, de dezembro de 2016, constitui a mais agressiva proposta de restrição de direitos da história da Seguridade Social, com ênfase na Previdência Social. Ainda que parcialmente modificada pelo seu relator, antes da submissão ao plenário da Câmara Federal, sua eventual aprovação ou de seu substitutivo trará prejuízos aos trabalhadores e aprofundará as desigualdades sociais no país, sob diversos ângulos.

Este artigo recupera brevemente o movimento de contrarreforma referente à Previdência Social desde a década de 1990 até as propostas para o seu aprofundamento, com a PEC no 287/2016 (ou o seu substitutivo), ressaltando o conteúdo de mudanças efetuadas até 2016 e das propostas em discussão, procurando mostrar relações entre elas, com base em seus

1. Questiona-se a dívida pública dos Estados-nação, incluindo o Brasil, por diversas razões, seja por sua ilegitimidade, devido à falta de transparência nas transações financeiras entre credores e os governos, seja pelos elevadíssimos encargos, devido aos juros altos, que multiplicam várias vezes o seu valor, ou ainda pelo comprometimento orçamentário com os seus serviços e amortizações inibindo os investimentos em políticas públicas e serviços essenciais à população. 
conteúdos e determinantes estruturais, destacando as pressões do capital financeiro, em diferentes conjunturas, para realizá-las,

Além desta introdução, o texto possui o desenvolvimento, sob o título "O movimento de contrarreforma da Previdência Social iniciado na década de 1990 e as tendências de seu aprofundamento sob o comando das finanças com a PEC n ${ }^{\circ}$ 287/2016”, o qual possui duas seções secundárias, “O movimento de contrarreforma entre 1998 e 2016" e "A PEC n 287/2016: conteúdo e consequências diante de sua eventual aprovação". Ao final, traz a conclusão.

\section{0 movimento de contrarreforma da Previdência Social iniciado na década de 1990 e as tendências de seu aprofundamento sob o comando das finanças, com a PEC n $n^{0} 287 / 2016$}

Ao longo de sua história, a Previdência Social passou por reformas ampliadoras de direitos - e por contrarreformas — restritivas de direitos. A mais importante reforma ocorreu em 1988, quando a ascensão das lutas sociais pressionou os deputados e senadores que compunham o Congresso Nacional Constituinte a incorporá-la, na nova Constituição Federal, ao sistema de Seguridade Social, que compreende os diretos de saúde, previdência e assistência social. Tal sistema possui um orçamento único, constituído por receitas de fontes de base diversificadas (como as contribuições de empregados, empregadores — destes sobre a folha de pagamento, receita ou faturamento e lucro - , contribuições dos importadores de bens ou serviços do exterior, contribuições sobre a receita de concursos de prognósticos, orçamentos dos governos das três esferas, entre outras), o que lhe possibilitou balanços superavitários ao longo dos anos, ${ }^{2}$ apesar das volumosas renúncias tributárias e desvios de recursos para outros fins, a exemplo da incidência da Desvinculação da Receita da União (DRU). ${ }^{3}$ Os objetivos da Seguridade

2. Entre outros, conferir publicações da Anfip disponíveis em: <http://www.anfip.org.br/publicacoes/ livros>. Acesso em: 7 abr. 2017.

3. A Desvinculação de Receita da União (DRU) é a terceira versão de instrumentos criados pelo governo federal para desvincular um percentual da arrecadação de impostos e contribuições da União, 
Social apontam para a universalidade de cobertura e atendimento, equidade de participação no custeio e gestão democrática. À época, a Previdência Social incorporou direitos como o valor mensal dos benefícios não inferior ao salário mínimo e a irredutibilidade desses valores vinculados ao último salário ou remuneração. Porém esse desenho da Seguridade Social — conquista dos trabalhadores - não agradou ao capital, que vê a Saúde e a Previdência como mercadorias lucrativas. Assim, nem chegou a ser todo implementado e tornou-se alvo de um movimento de contrarreforma, ora mais agressivo e com maior reação social, ora mais sutil e sem grandes reações, dependendo, entre outros fatores, dos instrumentos utilizados, da correlação de forças e do grau de subordinação do Estado às pressões do capital.

O contexto de crise nas últimas quatro décadas, em que também houve a expansão da questionável dívida pública dos Estados-nação e a afirmação das finanças no comando da acumulação (Chesnais, 2001), é o pano de fundo estrutural comum a esse movimento de contrarreforma da Previdência Social. A ele associam-se outros elementos conjunturais.

Essa crise que afeta a humanidade não é apenas financeira. O seu alcance mundial, prolongamento e consequências em diversas dimensões caracterizam-na como uma crise estrutural do capital (Mészáros, 2009). Todavia, em seu curso, uma das características do capitalismo é a centralidade do capital financeiro nas relações econômicas e sociais, associado a grupos industriais. Isso ocorreu porque a dívida dos Estados-nação forçou a liberalização dos mercados e políticas para atrair créditos, estimulando a expansão do mercado financeiro. Assim, “o poder das finanças foi construído

\footnotetext{
visando conter despesas e permitir a flexibilidade operacional ao Poder Executivo. O primeiro foi o Fundo Social de Emergência (FSE), criado em 1994 (Emenda Constitucional de Revisão n ${ }^{\circ}$ 1), com vigência até 1995, quando foi modificado e denominado Fundo de Estabilização Fiscal (FEF) (EC n $\left.{ }^{\circ} 17\right)$, que vigorou de 1996 a 1999. A DRU, com vigência a partir de 2000 ( $\mathrm{EC} \mathrm{n}^{\circ} 27$ ), desvincula de órgãos, fundos ou despesas $20 \%$ da arrecadação de impostos e contribuições da União para manter o superávit fiscal primário, principalmente para cumprir os compromissos da dívida pública. Em 2003, foi novamente renovada sob a mesma condição $\left(\mathrm{EC} \mathrm{n}^{\circ} 42\right)$. A EC n ${ }^{\circ} 56$, de 21 de dezembro de 2007, a prorrogou até 31 de dezembro de 2011, quando houve nova prorrogação até 31 de dezembro de 2015 por meio da $E C \mathrm{n}^{\circ} 68$. Em 8 de setembro de 2016, por meio da $\mathrm{EC} \mathrm{n}^{\circ} 93$, foi prorrogada até 31 de dezembro de 2023 , com elevação do percentual incidente para $30 \%$.
} 
sobre o endividamento dos governos" (Chesnais, 2001, p. 17), da política de juros altos e supervalorização do mercado de ações.

Para Chesnais (2001), ainda que os grupos industriais transnacionais detenham a condição de dominação política e social no capitalismo, em sua opinião não são eles que conduzem o movimento do conjunto da acumulação na atualidade:

Ao término de uma evolução de vinte anos, são as instituições constitutivas de um capital financeiro possuindo fortes características rentáveis que determinam, por intermédio de operações que se efetuam nos mercados financeiros, tanto a repartição da receita quanto o ritmo do investimento ou o nível e as formas do emprego assalariado. (Chesnais, 2001, p. 8)

As instituições as quais o autor se refere são os bancos e os chamados investidores institucionais, ou seja, as seguradoras, os fundos de pensão e as sociedades financeiras de investimento financeiro coletivo, administradoras de ativos para a conta de clientes dispersos (fundos mútuos) que, em geral, são as filiais fiduciárias dos grandes bancos internacionais ou das companhias de seguro.

Esses investidores institucionais, que ocupam lugar destacado na economia mundial, não teriam conquistado essa posição sem que tivessem sido alimentados pela dívida pública (Chesnais, 2001), que provoca forte pressão sobre o Estado quanto à destinação do fundo público e aos destinos das políticas e serviços públicos. Pois,

Sob o efeito de taxas de juros superiores [...] à inflação e ao crescimento do PIB, a dívida pública faz "bola de neve". Ela é geradora em seguida de pressões fiscais altas sobre as receitas menos móveis e mais fracas, de austeridades orçamentárias e de paralisia das despesas públicas. É ela, no decorrer desses últimos dez anos, que abriu a via para as privatizações. (Chesnais, 2001, p. 17)

Entre as organizações constitutivas do capital financeiro, os fundos de investimentos conquistaram grande poder nos últimos anos, dado ao espaço 
alcançado nos mercados financeiros. Segundo Gallino (2016, p. 230), ${ }^{4}$ esses fundos

\begin{abstract}
Alcançaram [...] ao final de 2007 [...] quase um terço do PIB mundial daquele ano. [um pouco mais de $50 \%$ ] correspondia aos contratos do tipo previdenciário - a maior parte individualizados — geridos por companhias de seguros, bancos e outros entes financeiros. [... assim] os fundos de pensão tornaram-se em menos de vinte anos um dos mais potentes grupos de investidores institucionais que existem no mundo.
\end{abstract}

Esse quadro explica por que nos últimos vinte anos no Brasil "os direitos previdenciários foram duramente atacados [...] para dar lugar à expansão da previdência dos fundos de pensão e das empresas de planos privados" (Silva, 2012, p. 449).

As pressões do capital financeiro sobre o Estado nem sempre aparecem de modo transparente. Todavia, três argumentos se repetem ao longo desse movimento de contrarreforma: o envelhecimento populacional e a ideia de crise, forjando a imagem de inviabilidade da previdência pública sob o regime de repartição; as alegações de altos custos do trabalho, forçando as renúncias tributárias em favor das empresas, reduzindo a participação do capital no custeio da previdência pública e ampliando a participação dos trabalhadores; a falácia de que os investimentos na previdência pública provocam o aumento da dívida pública dos governos e desequilibram os orçamentos (Silva, 2016). Assim, ao longo dos anos as medidas contrarreformistas justificaram-se com base nesses argumentos falaciosos.

Os instrumentos normativos utilizados nesse movimento de contrarreforma foram variados. As medidas que mais chamam a atenção são as viabilizadas por emendas à Constituição Federal. Mas a contrarreforma também ocorre por leis complementares, medidas provisórias, leis ordinárias, decretos ou por decisões gerenciais sob a forma de resoluções etc.

4. Luciano Gallino é italiano, ex-professor emérito da Universidade de Torino; faleceu em novembro de 2015. Tradução própria do italiano para o português. 


\subsection{0 movimento de contrarreforma entre 1998 e 2016}

O Brasil, na segunda metade da década de 1990, foi marcado pelos altos índices de desemprego e aprofundamento da pobreza em decorrência da crise do capital e pelo fortalecimento do projeto neoliberal, retomado pelo governo Collor e seguido pelo governo Fernando Henrique. Esse governo impulsionou a reestruturação produtiva com leis que restringiram os direitos trabalhistas, como a do contrato de trabalho por tempo determinado, das terceirizações, do incentivo às demissões dos servidores públicos pelo Programa de Demissão Voluntária (PDV). Além disso, realizou amplo processo de contrarreforma do Estado e de seu aparelho, privatizando empresas estatais, introduzindo na administração pública modelos gerenciais de bases mercadológicas, legalizando as transferências orçamentárias para as Organizações Sociais de Interesse Público (Oscip), imprimindo a tônica mercadológica à educação e inaugurando o movimento de contrarreforma na Seguridade Social, com ataques à Saúde e à Previdência Social. O cunho neoliberal de seu governo se expressa pela fiel observância às diretrizes do Consenso de Washington, pelos acordos com o Fundo Monetário Internacional, em torno da política econômica de austeridade fiscal, além de obediência às diretrizes do Banco Mundial, incluindo as do documento Envejecimiento Sin Crisis, de 1994 que recomenda mudanças nos sistemas de Previdência Social para criar poupança interna, com a valorização dos regimes de capitalização e a redução da extrema pobreza com os benefícios previdenciários (Banco Mundial, 1994), o que se traduz em enxugar a Previdência Social e expandir a previdência privada. Sobre o contexto, Hermida (2012, p. 1.454) é muito elucidativo:

Com as orientações advindas do Consenso de Washington, o governo FHC iniciou a reforma do Estado, impondo uma visão economista aos problemas sociais. Depois de ceder à vontade do capital internacional - através dos acordos assinados em 1998 e 1999 —, o governo de FHC entregou a direção política e econômica ao FMI. A partir da assinatura dos acordos, a política financeira brasileira ficou mais autônoma e volátil que nunca. Os acordos com o FMI, que ficaram conhecidos como os mais lesivos que o país já assinou 
na sua história, têm como objetivo principal o estabelecimento de metas para que a geração de recursos seja principalmente utilizada para o pagamento das dívidas privada e pública assumida.

É nesse contexto que a Emenda Constitucional (EC) n ${ }^{\circ} 20$, de 1998, inaugura o ciclo de restrições de direitos previdenciários, ou seja, o movimento de contrarreforma da Previdência Social.

Essa emenda atingiu sobretudo o Regime Geral de Previdência Social (RGPS), e as mudanças seguiram a lógica que move até o presente esse movimento de contrarreforma: a extinção elou reconfiguração de beneficios, redução de seus valores e tempo de usufruto e ampliação do tempo de contribuição. Entre as principais mudanças impostas pela $\mathrm{EC} \mathrm{n}^{\circ} 20$ destacam-se: o estabelecimento de um teto nominal de $\mathrm{R} \$ 1.200,00$ para os valores dos benefícios do RGPS, que à época correspondia a dez salários mínimos; as aposentadorias deixaram de ser por tempo de serviço para serem por tempo de contribuição; limitou-se o acesso às aposentadorias proporcionais e especiais - incluindo o fim da aposentadoria especial para professores universitários; foi prevista a previdência complementar para os servidores públicos a ser instituída; tentou-se vincular o tempo de contribuição à idade para fins de aposentadoria e, como não foi possível, excluiu-se a fórmula de cálculo dos benefícios da Constituição Federal, possibilitando a criação do fator previdenciário, por lei ordinária, em 1999, o que durou até meados de 2015, como regra geral para o cálculo de aposentadorias, reduzindo os seus valores em até $40 \%$. Além da fórmula de cálculo das aposentadorias, a EC $\mathrm{n}^{\mathrm{o}} 20$ promoveu uma grande desconstitucionalização dos direitos, transferindo suas regulamentações para leis ordinárias, a exemplo do cálculo dos valores de outros benefícios; os critérios de reajustamento de benefícios e do teto de seus valores e as contribuições sociais dos empregadores, incidentes sobre a folha de salários, receita ou faturamento e lucro.

No intervalo de tempo entre 1999 e 2003, o movimento de contrarreforma seguiu, porém sem chamar muito a atenção da sociedade. Bons exemplos são os reajustes do teto dos valores dos benefícios do RGPS e dos valores individuais dos benefícios desse regime. $O$ teto foi sendo 
rebaixado comparativamente ao salário mínimo, e atualmente corresponde a $\mathrm{R} \$ 5.531,31$, o equivalente a 5,9 salários mínimos, ${ }^{5}$ e a fórmula de reajustes dos valores dos benefícios os achataram sem assegurar-lhes o valor real. As renúncias tributárias do período também são restrições de direitos. Essas medidas, em geral, são sutis e não chamaram muito a atenção da população, inclusive por serem efetuadas por leis ordinárias.

Em 2003, o governo Lula assumiu o comando do país, com a economia estagnada, elevados índices de desemprego, além de grande comprometimento do Orçamento Geral da União com os serviços e amortizações da dívida pública. Entretanto, as diretrizes macroeconômicas de seu governo não mudaram substancialmente em relação ao governo anterior, ainda que tenham impulsionado o crescimento econômico entre 2004 e 2011 e a melhoria de alguns indicadores sociais. Quando assumiu o governo, o Produto Interno Bruto (PIB) naquele ano correspondeu a US\$ 560.155,4 milhões e o país estava na décima quinta posição entre as maiores economias do mundo. Quando deixou o governo, em 2011, o país ocupava a sexta posição entre as maiores economias, com o PIB de US\$ 2.613 bilhões. ${ }^{6}$ Quanto ao trabalho, durante o seu governo, houve elevação do valor real do salário mínimo, redução do tempo de procura de trabalho, porém ocorreu o aumento da rotatividade e dos trabalhos precários. Do total de "postos de trabalhos criados na primeira década do século XXI, 94,8\% foram com rendimentos de até 1,5 salário mínimo mensal" (Pochmann, 2012, p. 27).

Durante o seu governo, o mundo viveu um profundo agravamento da crise estrutural do capital. O colapso do setor imobiliário dos Estados Unidos, em 2008, foi o detonador para que a crise atingisse outras áreas e outros países, afetando, "pela primeira vez na história, a totalidade da humanidade" (Mészáros, 2011, p. 55) e provocando enormes consequências. As estratégias do governo Lula para minorar os seus efeitos, entre outras, basearam-se nas renúncias tributárias, favorecendo o capital produtivo, e no estímulo

5. Em 1998 o valor do salário mínimo era R\$ 120,00; em 2017 corresponde a R 937,00.

6. Informações do PIB disponível em: $<$ http://pt.tradingeconomics.com/brazil/indicators $>$. Acesso em: 10 abr. 2017. 
ao consumo. Para isso, utilizou-se do Programa Bolsa Família e dos benefícios previdenciários e assistenciais para estimular o consumo, chegando a conclamar pela mídia os aposentados e pensionistas a consumirem. Essa estratégia favoreceu a política de transferência de recursos monetários dos aposentados ao capital financeiro por meio dos empréstimos consignados em folha de pagamento dos aposentados da Previdência Social e de outras operações financeiras facilitadas pelo acesso dos bancos ao cadastro desses segurados, que se endividaram (Silva, 2015). Outra estratégia que atingiu a Seguridade Social foi a renúncia tributária. AEC n ${ }^{\circ} 47 / 2005$ foi a base dessa estratégia, como será mostrado.

Ainda no tocante ao movimento de contrarreforma da Previdência Social no governo Lula, as principais medidas ocorreram em seu primeiro ano de governo, por meio da Emenda Constitucional no 41, de 19 de dezembro de 2003, as quais foram complementadas ou revistas pela $\mathrm{EC} \mathrm{n}^{\circ} 47$ de julho de 2005. As medidas da $E C \mathrm{n}^{0} 41$ foram fortes e chamaram a atenção da sociedade, com reações dos setores atingidos. As justificativas, as diretrizes e as estratégias restritivas adotadas foram as mesmas de 1998, todavia, os Regimes Próprios de Previdência Social (RPPS), destinados aos servidores públicos, foram os mais atingidos, com o fim da aposentadoria integral, a vinculação do tempo de contribuição à idade para fins de aposentadoria - o que não foi aprovado para o RGPS em 1998, a contribuição previdenciária para aposentados e pensionistas sobre a parte da remuneração que ultrapassa o valor do teto dos benefícios do RGPS e a possibilidade de teto para aposentadoria dos servidores. A emenda estabeleceu que seria assegurado programa previdenciário para trabalhadores de baixa renda, exceto aposentadoria por tempo de contribuição.

Em julho de 2005, a EC n 47 retomou a possibilidade de aposentadoria com valores integrais para os servidores que tivessem ingressado no serviço público anterior a 16 de dezembro de 1998, data da promulgação da $E C n^{\circ} 20$; retirou a exceção de aposentadoria por tempo de contribuição dos programas previdenciários para trabalhadores de baixa renda, incluindo a garantia de benefício no valor de um salário mínimo - essa exclusão da Constituição Federal não impediu que fossem criados programas com essa 
exceção, como será visto; incluiu a possibilidade de as contribuições sociais dos empregadores terem alíquotas ou base de cálculo diferenciadas em razão da atividade econômica, da utilização intensiva da mão de obra, do porte da empresa ou condição estrutural do mercado de trabalho - essa medida possibilitou as renúncias tributárias, a partir da desoneração da folha de pagamento, reduzindo sobremaneira a participação dos empresários no custeio da Seguridade Social; transferiu para as leis ordinárias a regulamentação de programas previdenciários destinados a trabalhadores de baixa renda, estabelecendo que as alíquotas e carências para esses trabalhadores serão menores que as vigentes para outros segurados da Previdência Social — o que resultou no incentivo da ampliação da cobertura da Previdência pelas categorias em trabalho informal por meio de programas como o Microempreendedor, cujos segurados podem contribuir com uma alíquota de $5 \%$ sobre o salário mínimo, porém não têm direito a aposentadoria por tempo de contribuição - o que constitui uma restrição de direito, que impôs à Previdência Social uma estratificação de direitos conforme a alíquota de contribuição, distanciando-a mais ainda da visão de Seguridade Social.

Ainda no governo Lula foi criado o "Fórum Nacional de Previdência Social (FNPS), cuja duração oficial se deu entre 12 de fevereiro e 22 de agosto de 2007" (Silva, 2012, p. 411-412), com o propósito de debater novas propostas de mudanças para a Previdência Social. Ressalta-se que, entre as propostas em debate, apareceram a desvinculação do valor dos benefícios previdenciários e do Benefício de Prestação Continuada (BPC) da Assistência Social do valor do salário mínimo. Todavia,

Verificou-se desacordo quanto à desvinculação do salário mínimo do piso previdenciário e à diferenciação dos pisos previdenciários e pisos assistenciais. A bancada dos empresários argumentou ser necessária a desvinculação do piso previdenciário ao salário mínimo para se preservar a equivalência entre contribuição e renda de aposentadoria, no caso de crescimento do valor real do mínimo [...]. O próprio ministro da Previdência argumentou ser um entrave à elevação do valor real do salário mínimo a vinculação do piso previdenciário aos benefícios assistenciais. Contudo, governo e trabalhadores redigiram posição consensual onde consta que "deve-se preservar o piso assistencial 
vinculado ao salário mínimo conforme estabelecido na Constituição Federal de 1988, respeitando seus direitos básicos de cidadania”. (Lopez, 2009, p. 22)

Além disso, outro ponto de discussão foi a respeito dos novos critérios para as pensões por morte:

Discutiu-se também a definição de novos critérios para concessão de pensões por morte. Os itens mais importantes diziam respeito à necessidade de especificar critérios diferentes para concessão das pensões no caso de haver cônjuges com filhos ou sem filhos e/ou a consideração sobre a idade de início de recebimento da pensão por parte do cônjuge. Neste último caso, cônjuges jovens teriam um período de carência para inserir-se no mercado de trabalho. Após a carência, o recebimento da pensão seria encerrado. (Lopez, 2009, p. 20)

Esse fórum foi muito criticado, e o governo desistiu de implementar suas propostas naquele momento. Algumas delas foram recuperadas pelo governo Dilma e outras pela PEC n n $^{\circ} 87 / 2016$.

No governo Dilma, a situação da economia, sobretudo a partir de 2014, agravou-se bastante, com a redução do crescimento econômico, elevação da inflação, além da piora de outros indicadores sociais e do trabalho. Em 2014, o PIB foi US\$ 2.345 bilhões e em 2015 só alcançou US\$ 1.775 bilhões, rebaixando o país para a nona posição entre as maiores economias. Com o aprofundamento da crise, em 2015, a dívida pública atingiu $66,23 \%$ do PIB, ${ }^{7}$ De acordo com a Anfip, as renúncias tributárias em 2011 totalizaram R\$ 152 bilhões, e em 2015 esse valor alcançou R $\$ 276$ bilhões, um crescimento de 76\% (Anfip, 2016, p. 128), o que implica drástica redução do financiamento da Seguridade Social. As renúncias tributárias constituem uma das faces desse movimento de contrarreforma iniciado em 1998, que perpassam todos os governos desde a década de 1990, as quais não chamam muito a atenção da sociedade, seja pela complexidade da matéria, seja pelos mecanismos

7. Dados sobre PIB e dívida disponíveis em: $<$ http://pt.tradingeconomics.com/brazil/indicators $>$. Acesso em: 10 abr. 2017. 
utilizados - as leis ordinárias, entre outros instrumentos normativos que podem ser aprovados discretamente. No governo Dilma, as renúncias tributárias a partir da desoneração da folha foram consolidadas. ${ }^{8}$

Ainda no governo Dilma, em abril de 2012 foi autorizada a criação da Fundação de Previdência Complementar do Servidor Público Federal (Funpresp), para gerir planos de benefícios para os servidores dos três poderes, e o valor do teto de aposentadoria dos servidores públicos passou a ser igual ao teto do RGPS. A Funpresp executivo e a Funpresp judiciário passaram a funcionar em fevereiro de 2013, impulsionando a previdência complementar.

O considerável aumento na quantidade de patrocinadores, ocorrido em 2013, provém da entrada em funcionamento da entidade fechada de previdência complementar dos servidores públicos da União, denominada Funpresp, que conta atualmente com 203 patrocinadores, entre órgãos da administração direta, autarquias e fundações federais. (Previc, 2014, p. 16)

Em dezembro de 2014 as Medidas Provisórias $n^{\circ} \mathrm{s} 664$ e 665, convertidas respectivamente nas leis $\mathrm{n}^{\mathrm{o}} \mathrm{s} 13.135$ e 13.134 , de junho de 2015 , modificaram a pensão por morte, o auxílio-doença, a aposentadoria por invalidez, o auxílio-reclusão, o abono salarial, o seguro-desemprego, seguindo a mesma lógica restrita usada em outros momentos desse movimento de contrarrefor$m a$, ou seja, redução dos valores e tempos de usufruto e limitando o acesso dos trabalhadores a esses benefícios, por meio do aumento do tempo de contribuição para acessá-los e "criação de novas exigências, como o tempo de contribuição de dezoito meses e a convivência marital de pelo menos dois anos para acesso às pensões por morte, ${ }^{9}$ as quais, como regra, deixaram de ser vitalícias para todos “(Silva, 2016, p. 434). Nota-se que esses critérios já

8. A desoneração corresponde à substituição das contribuições previdenciárias incidentes sobre a folha de pagamentos, pela incidente sobre a receita bruta. Em 2014, com a MP n ${ }^{\circ} 651$, convertida na Lei n ${ }^{\circ} 13.043$, tornou-se definitiva essa mudança, o que tem contribuído para o (des)financiamento da Seguridade Social.

9. O Senado assegurou a exceção de acesso ao benefício por quatro meses para quem não cumprir esses dois critérios e os dispensou em situações de morte do segurado por acidente de qualquer natureza ou doença profissional/trabalho. 
vinham sendo debatidos desde o governo Lula. Tais medidas alcançaram tanto os servidores públicos quanto os trabalhadores da iniciativa privada, seguindo o propósito de aproximar os regimes, com base nos direitos mais limitados, para unificá-los (Silva, 2015). Algumas propostas que estavam previstas na MP n ${ }^{\circ}$ 664/2014, que não foram aceitas pelo Congresso Nacional, foram retomadas nas propostas de emenda constitucional do governo Temer, como a redução do valor das pensões para 50\% e a não reversibilidade ao cônjuge das partes destinadas a outros dependentes quando estes perderem o direito de usufruto.

O Decreto $\mathrm{n}^{\circ} 8.443$, de 30 de abril de 2015, instituiu o Fórum de Debate sobre Política de Emprego, Trabalho, Renda e Previdência Social, composto por representantes dos trabalhadores, dos aposentados, dos empregadores e do Poder Executivo com a finalidade de promover o debate a respeito dessas políticas e subsidiar a elaboração de propostas sobre as mesmas. Todavia, o agravamento da crise política que resultou no impeachment da presidenta da República, em agosto de 2016, não permitiu que novas medidas fossem adotadas sob o seu comando. Porém o Fórum apresentou o seu relatório em maio de 2016, o qual subsidiou as propostas de Temer, que seguem a mesma lógica.

Outro aspecto percebido no governo Dilma, de favorecimento ao capital financeiro, a partir da Previdência Social, foi o aprofundamento da política de transferência de recursos monetários aos bancos por meio dos empréstimos consignados realizados aos aposentados. Em 29 de outubro de 2015, o governo, com o apoio do Conselho Nacional de Previdência Social (CNPS), elevou os juros sobre os empréstimos do percentual de 2,14\% para $2,34 \%$, sendo que se o mesmo se destinar ao pagamento de cartão de crédito, o percentual sobe de 3,06\% para 3,36\%. Trata-se de medida administrativa, porém, contrarreformista. Na mesma direção, em 4 de novembro de 2015, a Lei $n^{\circ} 13.183$ ampliou a margem de empréstimo em relação aos valores de benefícios, passando de $30 \%$ para $35 \%$. Essa aliança entre o governo e o capital rentista provoca um criminoso endividamento dos aposentados e pensionistas. Em vez de segurança, estes passam a viver em profunda insegurança. Essas medidas visam favorecer o consumo, como forma de redução dos efeitos da crise, estratégia já usada por Lula. 
As medidas que vinham sendo empregadas para reduzir os efeitos da crise esgotaram-se. A economia encolheu e os indicadores sociais e de trabalho pioraram. O ano de 2015 fechou com a taxa de desemprego de $9 \%$, uma elevação de 2,5\% em relação ao final de 2014 (Ipea, 2016, p. 11). O rendimento médio real habitual dos ocupados caiu e a inflação elevou-se. Nesse contexto, a disputa pelo fundo público ampliou-se muito. Em 2015, de acordo a equipe da auditoria cidadã da dívida, foram destinados à dívida pública 42,43\% do Orçamento Geral da União, 22,69\% à Previdência Social, 4,14\% à Saúde, $3,91 \%$ à Educação, ${ }^{10}$ revelando o grande comprometimento do orçamento com os serviços e amortização da dívida. Em 2016, 43,94\% do orçamento destinou-se aos juros e amortizações da dívida e 22,54\% à Previdência Social. ${ }^{11}$ No ano de 2016, em função do agravamento da crise política, intensificaram-se as ameaças e perdas de direitos e a disputa pelo fundo público.

\subsection{A PEC n 287/2016: conteúdo e consequências diante de sua eventual aprovação}

Com o impeachment da presidenta da República, em 2016, a crise agudizou-se em várias dimensões.

No que se refere aos indicadores sociais e do trabalho, a Pesquisa Nacional por Amostra de Domicílios (PNAD/contínua) referente ao terceiro trimestre de 2016 estimou a taxa de desocupação do período em 11,8\%, o que equivale a mais de 12 milhões de pessoas desocupadas. O rendimento médio real habitual dos ocupados no período foi estimado em $\mathrm{R} \$ 2.015,00$ (menos 2,1\% em relação ao mesmo período de 2015). ${ }^{12}$ Outros indicadores também pioraram. A luta política intensificou-se.

10. Disponível em: <http://www.auditoriacidada.org.br/blog/2016/11/09/explicacao-sobre-o-grafico-do-orcamento-elaborado-pela-auditoria-cdada-da-divida/> . Acesso em: 27 nov. 2016.

11. Informação disponível em: < http://www.auditoriacidada.org.br/blog/2017/05/31/panfleto-explicativo-consulta-nacional/>. Acesso em: 30 ago. 2017.

12. Disponível em: <ftp://ftp.ibge.gov.br/Trabalho_e_Rendimento/Pesquisa_Nacional_por_Amostra_de_Domicilios_continua/Trimestral/Comentarios_Sinteticos/pnadc_201603_trimestre_comentarios_sinteticos_Brasil.pdf>. Acesso em: 27 nov. 2016. 
Nesse cenário de crise nas dimensões econômica, política e social, o governo Temer intensifica ao extremo a política de austeridade fiscal. O propósito explícito do governo é reduzir investimentos em políticas públicas para elevar o superávit primário e garantir os compromissos em torno da dívida pública. Assim, se nos anos anteriores o fundo público já estava orientado para os interesses do capital, no governo Temer piorou de modo acelerado. Uma medida drástica nessa direção foi a instituição do novo regime fiscal e da seguridade por meio da Emenda Constitucional n ${ }^{\circ}$ 95/2016, que congela os limites constitucionais para as despesas primárias da administração pública federal (aquelas que não envolvem juros - Saúde, Educação, Assistência Social, Defensoria Pública etc.) por vinte anos, sob o velho argumento de que investir em políticas sociais amplia a dívida pública. Tais limites serão apenas corrigidos pela inflação de um para outro exercício financeiro, ainda que cresçam a economia e as demandas sociais. Os limites só serão alterados depois de dez anos de vigência do novo regime. O não cumprimento dos limites implicarão vetos aos servidores públicos, como aumento e/ou reajustes salariais, adequação de remuneração, a criação de cargos, alteração de carreiras, admissão ou contratação de pessoal e realização de concurso público, entre outros. O novo regime é um grande retrocesso; na realidade, sua finalidade precípua é direcionar mais recursos para os juros e amortizações da dívida pública, uma vez que as despesas financeiras não foram limitadas e são estas que comprometem o orçamento público, como diz Salvador, "o que de fato compromete muito o orçamento público são os gastos destinados ao capital portador de juros". ${ }^{13}$ A Anfip (2016, p. 126) acrescenta que "em 2015, a despesa [R $\$ 501.8$ bilhões] com os juros [da dívida pública] superou a despesa com os benefícios previdenciários, que foi de $\mathrm{R} \$ 436.1$ bilhões”.

Simultaneamente ao debate sobre o novo regime fiscal, o governo anunciou as contrarreformas trabalhista e previdenciária. Em relação ao trabalho, as propostas aprovadas em julho de 2017 vão desde a elevação da jornada de trabalho, passando pela terceirização plena até o trabalho intermitente.

13. Evilásio Salvador. Disponível em: $<$ http://www.mvermelho.org.br/noticia/288771-1>. Acesso em: 27 nov. 2016. 
Quanto à Previdência Social, a proposta é uma afronta social e visa sua entrega ao capital financeiro.

A primeira medida do governo Temer quanto ao desmonte da Previdência Social foi a extinção do Ministério da Previdência Social e Trabalho, mudando os órgãos estratégicos de formulação, gestão e controle da Previdência Social para a Fazenda e o órgão de execução (Instituto Nacional do Seguro Social - INSS) para o Ministério Desenvolvimento Social e Agrário. ${ }^{14}$ Apesar das manifestações contrárias, o governo não recuou. Em maio de 2017, por meio da MP n ${ }^{\circ} 782,{ }^{15}$ a competência em matéria de Previdência foi explicitada como da Fazenda. Com isso, sinalizou que seria o Ministério da Fazenda a conduzir, nessa conjuntura, o movimento de contrarreforma da Previdência Social, condição em que as influências do capital financeiro estão sendo favorecidas.

As principais propostas de contrarreforma da Seguridade Social, com ênfase na Previdência Social do governo Temer, contidas na PEC $\mathrm{n}^{\mathrm{o}}$ $287,{ }^{16}$ são: idade mínima de 65 anos e um tempo mínimo de contribuição de 25 anos, para fins de aposentadoria, para homens e mulheres de todos os setores; o valor da aposentadoria correspondente a $51 \%$ da média das remunerações e salários de contribuição, acrescido de $1 \%$ por cada ano de contribuição no momento da aposentadoria, para se alcançar $100 \%$ da média, deve-se contribuir por 49 anos, o que constitui uma afronta aos contribuintes; aumento da idade mínima de 65 anos, após cinco anos da vigência da PEC, conforme seja o incremento da esperança de sobrevida após 65 anos de idade, estimado pelo IBGE; fim das aposentadorias especiais para professores do ensino fundamental e trabalhadores em áreas de risco - permanecem aquelas para pessoas com deficiência e trabalhadores

14. Cf. MP n ${ }^{\circ} 726$, de 12/5/2016, aprovada em 8/9/2016 pelo Senado e transformada na Lei $\mathrm{n}^{\circ} 13.341$, de 29/9/2016.

15. Disponível em: <http://www.planalto.gov.br/ccivil_03/_ato2015-2018/2017/Mpv/mpv782.htm>. Acesso em: 24 jun. 2017.

16. Proposta de Emenda à Constituição $P E C n^{\circ} 287$, encaminhada à Câmara dos Deputados em 5/12/2015. Disponível em: <http://static.congressoemfoco.uol.com.br/2016/12/PEC-287-2016.pdf >. Acesso em: 6 abr. 2016. 
que tenham a saúde "efetivamente" afetada pelo ambiente, com 50 e 55 anos de idade, respectivamente; aposentadoria compulsória do servidor público aos 75 anos — idade a ser aumentada conforme a regra geral, e valor de benefício igual à divisão do total de anos de contribuição por 25 , multiplicado pelos $51 \%$ da média das remunerações; proibição de criação de novos RPPS pelos estados e municípios, sendo que os entes federados que mantiverem o regime devem fixar o teto do RGPS para a aposentadoria e criar a previdência complementar; mudança da alíquota de contribuição do trabalhador rural (segurado especial) de 2,1\% sobre a comercialização de seus produtos, valendo para o grupo familiar, para uma alíquota individual sobre o salário mínimo, a ser definida em lei; proibição de acumular duas aposentadorias - exceto nos casos previstos na Constituição Federal uma aposentadoria e uma pensão por morte do cônjuge ou duas pensões por morte de cônjuges; redução dos valores das pensões de $100 \%$ para $50 \%$, com $10 \%$ para cada dependente até $100 \%$, sendo que as partes dos dependentes prescritas não serão reversíveis ao cônjuge; elevação da idade para acesso ao BPC por pessoas idosas de 65 para 70 anos, que aumentará, conforme regra geral, após dez anos de vigência; desvinculação do valor do BPC do valor do salário mínimo; para pessoas com deficiência, a lei definirá novo conceito de família, os critérios de avaliação do grau da deficiência e definição do valor do benefício, além de estabelecer que a renda total de todos os membros da família devem compor o cálculo da renda familiar per capita, entre outras. Conforme a $\mathrm{PEC} \mathrm{n}^{\circ} 287 / 2016$, as novas regras de Previdência valerão para os novos contribuintes e para os homens com menos de cinquenta anos de idade e as mulheres com menos de 45 , que já contribuem. Os demais cumprirão regras de transição correspondente ao tempo restante de contribuição e mais $50 \%$ sobre ele, entre outras.

O texto original foi debatido em instâncias da Câmara dos Deputados. Em 19 de abril de 2017 foi emitido relatório preliminar e parecer do relator. ${ }^{17}$

17. Relatório da Comissão Especial da PEC nº 287/2016, sob coordenação do relator Arthur Maia. Disponível em: <http://www.valor.com.br/sites/default/files/infograficos/pdf/parecerreformanovo.pdf $>$. Acesso em: 20 abr. 2017. 
Em 3 de maio, a Comissão Especial destinada a emitir o parecer sobre a PEC aprovou o substitutivo final a ser votado pelo plenário da Câmara. ${ }^{18}$

Assim, a Comissão Especial reduziu a idade mínima de mulheres urbanas para aposentadoria para 62 anos e as rurais para 57 anos; a idade dos homens urbanos ficou em 65 anos e os rurais em 60 anos. A contribuição para esses trabalhadores rurais retornou aos quinze anos atuais, porém de modo individual em alíquota de contribuição igual aos trabalhadores urbanos de baixa renda para uma aposentadoria no valor de um salário mínimo. $\mathrm{O}$ valor da aposentadoria, cumpridos os requisitos de idade mínima e tempo de contribuição, foi sugerido para $70 \%$ da média das contribuições, e para se alcançar $100 \%$ da média serão necessários quarenta anos de contribuição, pois nos primeiros cincos anos, após o mínimo exigido, cada ano de contribuição corresponderá a 1,5\% da média; no segundo quinquênio, cada ano corresponderá a $2 \%$, e no terceiro, a 2,5\%. Foi restabelecida a possibilidade de aposentadoria integral para as situações de invalidez por acidente do trabalho ou doença profissional. Com relação às aposentadorias especiais de área de "risco", não houve mudança da perspectiva atribuída pela PEC, porém reduziu-se a idade para aposentadoria de professores da rede básica para 60 anos, sendo 25 anos de contribuição (homens e mulheres); os policiais terão aposentadoria com 55 anos de idade e 25 anos de atividade policial. A idade para aposentadoria compulsória do servidor público continuou 75 anos, e o cálculo do benefício será proporcional ao tempo de contribuição, seguindo a regra geral. A acumulação de benefícios de aposentadorias, bem como de aposentadoria e pensão poderá ocorrer até o valor de dois salários mínimos, e manteve-se a vinculação do valor mínimo ao valor do salário mínimo. Quanto ao BPC para idosos, a idade foi reduzida para 68 anos e manteve-se a vinculação do valor do benefício ao salário mínimo. Já para pessoas com deficiência, foi retirada a vinculação do grau de deficiência ao valor do benefício e a obrigatoriedade de inclusão da renda decorrente de

18. O relatório definitivo da $\mathrm{PEC} \mathrm{n}^{\circ} 287$, de 5/12/ 2016, foi aprovado pela Comissão Especial em 3/5/2017 e o parecer do relator foi encaminhado para publicação no dia do mesmo mês. Assim, a PEC encontra-se no momento pronta para votação no Plenário. 
benefícios sociais no cálculo da renda familiar per capita; o valor será de um salário mínimo. Quanto às regras de transição para os que já estão trabalhando, criou-se uma escala móvel para a idade que entrará em vigor a partir da aprovação da PEC e mudará a cada dois anos, aumentando um ano até o limite; reduziu-se o acréscimo ao tempo de contribuição restante de $50 \%$ para $30 \%$. Assim, para os que se vinculam ao RGPS, a idade de partida será 53 anos, se mulher, e 55, se homem. Para os servidores públicos, a idade de partida será 55 anos para mulheres e 60 para os homens. Há variações para as transições das aposentadorias especiais de policiais e outros. A Comissão criou a possibilidade de contratação, pelo Estado, de entidades de previdência complementar privada que não tenham sido criadas exclusivamente para atender aos servidores públicos. Além dessas alterações, retirou-se da proposta os magistrados e os membros do Ministério Público.

Nota-se que não houve mudanças substanciais, de modo que se essas propostas substitutivas forem aprovadas ${ }^{19}$, a eliminação de direitos continuará sem precedentes na história da Seguridade Social e imporá grande fratura à mesma, deixando as camadas mais pobres sem proteção e impulsionarão a previdência complementar - este é o seu maior objetivo.

As desigualdades sociais tendem a ser ampliadas entre ricos e pobres, uma vez que a renda básica das pessoas mais pobres é composta, sobretudo, pelas aposentadorias e pensões, as quais terão dificuldades de ter acesso a partir das novas regras. Da mesma forma, tendem a aumentar as desigualdades entre as regiões geográficas do país, na medida em que o Norte e o Nordeste do Brasil possuem as menores expectativas de vida, como é o caso dos homens dos estados do Piauí, Maranhão e Alagoas, cuja média de esperança de vida é 66 anos (IBGE, 2015, p. 15), os quais terão maiores dificuldades para acessar os benefícios e, caso o façam, os usufruirão por pouco tempo. As mulheres serão muito prejudicadas, as desigualdades entre homens e mulheres, sob diversos ângulos, serão desconsideradas para fins de aposentadoria, especialmente a jornada de trabalho mais extensa por

19. Até o momento de fechamento do artigo, o substitutivo não havia sido voltado e discutia-se no âmbito do governo a possibilidade de novas alterações em forma de proposta aglutinativa. 
assumirem maiores responsabilidades domésticas e com os cuidados com os filhos e pessoas doentes na família. Elas são a maioria nas aposentadorias por idade e também as principais beneficiárias das pensões. Assim, terão também nesses itens os maiores prejuízos. Dessa forma, o país andará para trás no quesito relações sociais entre os sexos. Em vez de impulsionar a igualdade entre homens e mulheres, as desigualdades serão aprofundadas. Estas desigualdades também tenderão a crescer entre os pequenos e médios municipios e os de grande porte, uma vez que a economia dos primeiros é movimentada, sobretudo, pelo volume de recursos decorrente dos benefícios previdenciários, pois uma particularidade da qual poucos têm conhecimento é que, segundo pesquisa de Álvaro Sólon, no ano de 1998, em 60,97\% dos municípios brasileiros o pagamento de benefícios previdenciários superava o fundo de participação municipal (França, 2000, p. 15). Os jovens também serão muito prejudicados, pois diante de um desemprego crescente, com elevada rotatividade, não conseguirão manter-se em emprego ininterruptamente por 49 anos (ou que seja, quarenta conforme relatório preliminar) para poder ter direito a aposentadoria. Assim, poderá haver uma redução de jovens pobres nas universidades porque tenderão a escolher os cursos profissionalizantes de curta duração na tentativa de ingressar mais cedo no mercado de trabalho. Da mesma forma, poderá haver maior evasão escolar no ensino fundamental. $\mathrm{O}$ acesso limitado ao BPC pelos idosos não permitirá que o benefício cumpra o objetivo de assegurar a sustentação da vida dessas pessoas. Sendo aprovadas as regras apontadas no substitutivo do relator, a situação não melhorará muito, na medida em que as exigências fundamentais referentes à idade e tempo de contribuição sofreram pouquíssimas alterações.

Portanto, este é um momento agudo da contrarreforma da Previdência Social. O capital financeiro não apenas será o grande beneficiado, na medida em que os trabalhadores com maiores rendimentos serão expulsos da previdência pública devido às regras restritivas e tenderão a buscar a previdência complementar pública ou privada. Na realidade, o grande capital esteve no comando da elaboração das propostas e pressiona por sua aprovação. Não por acaso, o secretário de Previdência que elaborou a proposta é membro do Conselho de Administração da BrasilPrev, um dos maiores fundos de 
pensão do país, ${ }^{20}$ e durante o tempo em que a elaborou recebeu diversos representantes das instituições constitutivas do capital financeiro, conforme denunciou a revista Carta Capital:

\begin{abstract}
Durante o período de gestação da reforma previdenciária, o secretário da Previdência Social, Marcelo Caetano, dedicou sua atenção ao mercado financeiro, empresas privadas e representantes patronais e menos aos trabalhadores. Levantamento de Carta Capital mostra que, dos 70 compromissos publicados na agenda de Caetano desde que assumiu o cargo, em 21 de julho, 21 foram com representantes de bancos, fundos de pensão e fundos de investimento e três com organizações patronais. ${ }^{21}$
\end{abstract}

Assim, seguindo essa lógica imposta pelo capital financeiro, a previdência pública torna-se cada vez mais diminuta, estratificada quanto aos direitos e com reduzido potencial de expansão. Mantém-se a tendência de uma previdência pobre, para poucos pobres (Silva, 2015). Em agosto de $2016,68,72 \%$ dos benefícios eram iguais a um salário mínimo e 84,23\% até dois salários mínimos. (Brasil, 2016, p. 30). A tendência é que esses percentuais se ampliem. A previdência será pobre também em relação à diversidade de situações cobertas, ainda existem categorias de trabalhadores sem a cobertura adequada, como as donas de casa, e a tendência é piorar. Para poucos pobres porque o teto dos valores dos benefícios diminui e as exigências para o acesso aos benefícios aumentam.

A alegação do déficit da Previdência Social tem sido usada para reduzi-la. Porém, não existe um orçamento da Previdência, mas um orçamento da Seguridade Social, como já foi dito, o qual tem sido superavitário, apesar das renúncias fiscais e dos desvios de recursos para outros fins. A Desvinculação das Receitas da União (DRU) só em 2015 retirou-lhe R\$ 63 bilhões (Anfip, 2016, p. 36). Mas, apesar da incidência da DRU e "das quedas na

20. Informação disponível em: $<$ http://www.conjur.com.br/2017-fev-23/sindicato-denuncia-secretario-previdencia-conflito-interesse>. Acesso em: 6 abr. 2017.

21. Disponível em: $<$ https://www.cartacapital.com.br/politica/agenda-de-secretario-da-previdencia-e-dominada-pelo-mercado-financeiro>. Acesso em: 17 abr. 2017. 
arrecadação, o orçamento da Seguridade Social em 2015 apresentou um resultado de R\$ 11,2 bilhões, inferior aos R \$ 55,7 bilhões de 2014" (Anfip, 2016, p. 27), o que mostra a falácia do argumento do débito.

No que se refere ao argumento do envelhecimento populacional, segundo as estimativas do Instituto Brasileiro de Geografia e Estatística (IBGE), em 2014 a estimativa da população com sessenta anos e mais de idade era 13,7\%; para 2030, a estimativa é $18,6 \%$, e para 2060, é 33,7\%. Assim, o Brasil é um país jovem. Em 2014, cerca de 89,3\% da população tinha menos de sessenta anos; em 2060, estima-se que esse índice será de $66,3 \%{ }^{22}$ Portanto, não é este também o real motivo das propostas destrutivas da Previdência Social.

O que está determinando a agudização desse movimento de contrarreforma da Previdência Social neste momento conjuntural é a força imperativa do capital financeiro sobre o Estado brasileiro. É para atender aos seus interesses que a Previdência Social está desmontada.

\section{Conclusão}

A crise estrutural do capital, no cenário de acumulação sob o comando das finanças, aprofunda-se em todas as dimensões e afeta a humanidade de diversas formas. Neste contexto de aprofundamento da crise, as dívidas públicas dos Estados-nação, a exemplo do Brasil, tem pressionado para a reorientação do fundo público em favor do capital, seja pela redução dos investimentos em políticas sociais e maior destinação de recursos para os serviços e amortização da dívida, seja pela via da privatização. O novo regime fiscal instituído no Brasil em 2016 e as contrarreformas trabalhistas e previdenciárias em curso são exemplos. Assim, o capital financeiro, que, associado aos grupos transnacionais, comanda a acumulação, comanda também as destinações dos recursos do orçamento público e os destinos das

22. IBGE, Pesquisa Nacional por Amostra de Domicílios 2004/2014 e Projeção da População do Brasil por Sexo e Idade para o Período 2000-2060 — Revisão 2013. Todos os dados disponíveis em: $<$ http://biblioteca.ibge.gov.br/visualizacao/livros/liv95011.pdf>. Acesso em: 27 nov. 2016. 
políticas sociais dos países endividados, como tem ocorrido no Brasil. Os cofres dos credores dos títulos públicos são destinos certos da maior fatia desses orçamentos, em detrimento das políticas e serviços públicos e garantia de direitos conquistados pelos trabalhadores. Assim, mais do que nunca é preciso exigir auditoria dessa dívida pública ilegítima, é preciso quebrar o ciclo vicioso que ela cria de modo a alimentar a expansão e o fortalecimento do mercado financeiro em detrimento de melhores condições de vida e redução das desigualdades sociais por meio de políticas públicas universais. Só a luta dos trabalhadores será capaz de mudar o rumo desta história, eliminado os males prolongados, como o movimento de contrarreforma da Previdência Social no Brasil que se prolonga por quase vinte anos.

Recebido em 24/4/2017 - Aprovado em 17/10/2017

\section{Referências bibliográficas}

ANFIP. Análise da Seguridade Social 2014. Brasília: Anfip, jul. 2015. . Análise da Seguridade Social 2015. Brasília: Anfip, jul. 2016.

BANCO MUNDIAL. Envejecimiento sin crisis: políticas para la protección de los ancianos y la promoción del crecimiento. Washington, D.C.: Oxford University Press, 1994.

BRASIL. Ministério da Previdência Social. Boletim estatístico da Previdência Social. Brasília: MPS, 2016. V. 21, n. 8.

CHESNAIS, François. Mundialização: o capital financeiro no comando. Outubro, n. 5, fev. 2001.

FRANÇA. A. S. A Previdência Social e a economia dos municípios. Brasília: Anfip, 2000.

GALLINO, Luciano. Finanzcapitalismo: la civiltà del denaro in crisi.Turim: Einaudi, 2016.

HERMIDA, Jorge Fernando. A reforma educacional na era FHC (1995/1998 e 1999/2002): duas propostas, duas concepções. In: IX SEMINÁRIO NACIONAL DE ESTUDOS E PESQUISAS “HISTÓRIA, SOCIEDADE E EDUCAÇÃO NO BRASIL”. 
Anais eletrônicos. João Pessoa: Universidade Federal da Paraíba, 31 jul. a 3 ago. 2012. Disponível em: <http://www.histedbr.fe.unicamp.br/acer_histedbr/seminario/ seminario9/PDFs/2.48.pdf>. Acesso em: 17 abr. 2017.

INSTITUTO BRASILEIRO DE GEOGRAFIA E ESTATÍSTICA (IBGE). Tábua completa de mortalidade para o Brasil - 2014: breve análise da evolução da mortalidade no Brasil. Rio de Janeiro: IBGE, 2015. Disponível em: <ftp://ftp.ibge.gov.br/Tabuas Completas_de_Mortalidade/Tabuas_Completas_de_Mortalidade_2014/notastecnicas. pdf>. Acesso em: 6 dez. 2016.

INSTITUTO DE PESQUISA ECONÔMICA APLICADA (IPEA). Mercado de Trabalho. Conjuntura e Análise, Brasília, abr. 2016.

LOPEZ, Felix Garcia. Fórum Nacional de Previdência Social: consensos e divergências. Texto para Discussão n. 1432. Brasília: Ipea, 2009. Disponível em: <http://www.ipea. gov.br/portal/images/stories/PDFs/TDs/td_1432.pdf>. Acesso em: 10 abr. 2017.

MÉSZÁROS, István. O desafio e o fardo do tempo histórico. Tradução Ana Cotrim e Vera Cotrim. $1^{\mathrm{a}}$ ed. revista. São Paulo: Boitempo, 2011.

. A crise estrutural do capital.Tradução: Francisco Raul Cornejo. São Paulo: Boitempo, 2009.

SUPERINTENDÊNCIA DE PREVIDÊNCIA COMPLEMENTAR (PREVIC). Informe da previdência complementar 2014: Secretaria de Previdência Complementar. Disponível em: <http://www.previdencia.gov.br/wp-content/uploads/2015/04/Informede-previdencia-complementar.pdf>. Acesso em: 27 jul. 2015.

POCHMANN, M. Nova classe média? O trabalho na base da pirâmide social brasileira. São Paulo: Boitempo, 2012.

SILVA, Maria Lucia Lopes da. Previdência Social no Brasil: (des)estruturação do trabalho e condições para a sua universalização. São Paulo: Cortez, 2012.

. Trabalho e Previdência Social no Brasil no contexto da crise do capital. $O \mathrm{Ser}$ Social em Questão, Rio de Janeiro, v. 1, n. 34, p. 137-160, $2^{\circ}$ semestre 2015.

. Crise, trabalho e "financeirização" da Previdência Social na Itália e no Brasil.

Ser Social, Brasília. v. 18, n. 39, p. 407-433, jul./dez. 2016.

Este é um artigo de acesso aberto distribuído nos termos de licença Creative Commons.

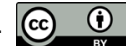

